\title{
The Integration of the Real Estate Market and the Stock Market: Some Preliminary Evidence
}

\author{
Crocker H. Liu, New York University \\ David J. Hartzell, University of Northern California \\ Wylie Greig, Vice President and Director of Research. The RREEF Funds \\ Terry V. Grissom, Texas A\&M University
}

The current study investigates whether the commercial real estate market is segmented from the stock market using the framework of Jorion and Schwartz (1986). Evidence is found to support the hypothesis that segmentation does exist as the result of indirect barriers such as the cost, amount, and quality of information for real estate rather than legal constraints. However, this evidence is contingent on whether real estate returns are computed with appraised values or imputed sale prices and on which market proxy is chosen.

No real estate investment study thus far has investigated the extent to which real estate markets are segmented from capital markets or whether any super risk premium arises as the result of this segmentation. This issue is important given the increased trend toward real estate securitization. The existence of super risk premiums would suggest that more securitization is needed to complete the markets. Therefore, the purpose of this study is to explore empirically whether the commercial nonfarm real estate market is segmented from the stock market using the framework of Jorion and Schwartz (1986). This approach allows one to distinguish not only whether indirect or legal investment barriers are the prime catalyst for market segmentation but also whether a super risk premium arises as the result of segmentation in the context of the Capital Asset Pricing Model (CAPM). For purposes of this article, we shall define integration and segmentation as follows:

- Integration: Integration exists if the only risk that is priced for both real estate and stocks is the systematic risk relative to the overall market index. No additional premium is therefore associated with real estate market risk. Investors thus earn the same riskadjusted expected return on stocks and commercial real estate. 
- Segmentation: Segmentation arises if the only risk that is priced for real estate is systematic risk relative to the commercial real estate market. Investors, therefore, do not necessarily earn the same expected return on commercial real estate and stocks.

Segmentation might exist for real estate since some institutional investors have a statutory constraint on the amount of investment funds that they can allocate to commercial real estate. In contrast, other institutional investors have a self-imposed policy constraint on real estate investment based on asset allocation models and other considerations.

This study contributes to the literature through applying the existing methodology in finance to address the issue of whether the commercial real estate market is segmented from the stock market and whether a super risk premium arises as the result of any market segmentation. No investigation of this issue has appeared thus far in the literature, although related literature exists on whether the domestic stock market is segmented from the foreign stock markets. Related literature also exists on whether one real estate market is segmented from another real estate market. A distinctive feature of this study is that commercial nonfarm real estate returns computed with both appraised values and imputed sales prices are employed to evaluate whether smoothed returns create the illusion that segmentation exists. Six different market proxies are also used to investigate if market segmentation arises from omitted asset markets. Neither the consequence of using appraisal-based returns or of omitting asset submarkets in the market proxy is addressed in the Jorion and Schwartz study on which this study is modelled.

We find evidence that the existence of segmentation is contingent not only on whether real estate returns are computed with appraised values or imputed sale prices but also on which market proxy is chosen. The analysis of returns computed with appraisal data indicates that indirect barriers such as the cost, amount, and quality of information represent the major source of segmentation. This finding is invariant to which market proxy is used. On the other hand, it is unclear whether the commercial real estate market is integrated with or segmented from the stock market and also whether segmentation, if it exists, is attributable to indirect barriers or legal constraints when imputed sale prices are used to compute returns. Further, the market proxy chosen is found to influence which type of investment barrier-legal or indirect-is responsible for segmentation. Which set of real estate returns are used also impacts on which version of the CAPM holds. The Sharpe- Lintner version of the CAPM obtains when appraisal-based returns are employed, while the Black version of the CAPM holds if real estate returns are based on imputed sale prices. 
The article proceeds as follows. Section 1 reviews the finance literature on inter-asset market segmentation as an initial point of departure. A summary of the data sources used, statistical properties of the data, and the construction of market indices are given in section 2. Section 3 discusses the methodology. Test results for integration and for segmentation of the commercial real estate market and stock market are given in section 4, and section 5 concludes the study.

\section{Literature Review}

No real estate investment study has investigated whether segmented real estate and capital markets exist or whether a super risk premium arises for real estate as the result of this segmentation. ${ }^{1}$ No research also exists on the extent to which real estate securitization has integrated the real estate and capital markets. Literature from a related discipline is therefore helpful in gaining an insight into the nature of the problem and the appropriate methodology to use.

The finance literature provides a useful point of departure for investigating whether inter-asset market segmentation leads to a super risk premium for risk which is unique to a given market such as commercial real estate. Most finance studies suggest that market segmentation can compromise the risk-return pricing paradigm with segmentation explored with respect to a legal imperfection. However, indirect impediments such as information difficulties might also result in market segmentation. In addition to this, market segmentation can also arise from a misspecification of the market portfolio. For example, Roll (1977) shows that the Blume and Friend (1973) conclusion, that segmented stock and bond markets might exist, occurs since the study uses a poor market proxy. To investigate whether segmentation exists, most finance research typically uses the CAPM as the initial point of departure although some studies use correlation analysis to evidence segmentation. However, low correlations do not necessarily indicate that segmentation is present if no investment barriers exist.

The empirical evidence on the existence of segmented security markets is mixed. Both Stehle (1977) and Errunza and Losq (1985) are unable to reject whether the U.S. stock market is segmented from or integrated with a foreign stock market due in part to a weak power of their tests. ${ }^{2}$ In contrast, Stapleton and Subrahmanyam (1977) demonstrate numerically that different asset prices are associated with different market structures given a CAPM world. Jorion and Schwartz (1986) also find that segmentation influences asset pricing using the same procedure as Stehle but with a more powerful test. $^{3}$ 
The current study follows the same procedure as Jorion and Schwartz (1986) to investigate whether the commercial real estate market is integrated with or segmented from the stock market. An elaboration of the methodology follows a discussion of the data used in this study.

\section{Data}

\section{Asset Return Series}

Quarterly holding period returns are computed for commercial nonfarm real estate returns and equity REITs for the period from June 1978 through September 1986. The availability of time series data for commercial, nonfarm real estate dictates the time interval evaluated ${ }^{4}$ The sources of data that underlie the return calculations for each asset category follows:

1. Equity Real Estate Investment Trusts (ERETT): Eighteen ERETTs that possess continuous prices and dividends over the study period are evaluated in the current study. Quarterly prices, dividends, and the number of shares outstanding for each EREIT are extracted from the COMPUSTAT tapes and Standard and Poor's (S\&P) Security Owner's Stock Guide.

2. Commercial Nonfarm Real Estate: Commercial nonfarm real estate returns are constructed from several sources. The first source consists of 22 quarterly return indices from the National Council of Real Estate Investment Fiduciaries (NCREEF) in conjunction with the Frank Russell Company (FRC). The total FRC index is also used in the current study. The FRC indices are value weighted appraisal indices with all properties in the index unlevered.

Commercial real estate returns are also computed with imputed sale prices. To impute prices, quarterly net operating income (NOI) per square foot for nine regional property types are obtained from a large, diversified, commingled real estate fund (CREF). Quarterly cap rates for these regional property types gathered from the American Council of Life Insurance Companies' (ACLI) publication Mortgage Commitments on Multifamily and Nonresidential Properties are divided into the respective NOI to yield imputed prices. ${ }^{5}$

Appendix A lists the specific real estate securities or real estate associated with each real estate category. 


\section{The Market Indices}

Six value-weighted market proxies are used to investigate whether the stock market is segmented from the commercial real estate market. The first market index is the S\&P500 which proxies for a portfolio of stocks of companies that are well capitalized, i.e., large firms. Market proxy 2 is the Media General Composite Index (MGCI) reported in the Media General Financial Weekly. This index includes stocks of small capitalized firms in addition to stocks of large capitalized firms. ${ }^{6}$ The third index, known as the security market index (SMI), combines the $\mathrm{MGCl}$ with corporate bonds, government bonds, mortgage-backed bonds, and cash equivalents. Index 4, hereafter referred to as the U.S. market index (USMI), adds commercial real estate, farms, and single-family homes to the SMI proxy. A valueweighted return index constructed from returns imputed from the ACLI data is used for the commercial real estate component. As an alternative to imputed commercial real estate returns, the value weighted FRC index is used with the resulting market proxy denoted USMI2. Alternative versions of the USMI index are used to explore whether segmentation is sensitive to the composition of the real estate component in the market proxy. The weights used to construct the USMII and USMI2 are shown in table 1 . The returns on various asset categories and the market values used to construct the portfolio weights are discussed in Appendix B. The sixth index is the investable capital market (ICM) obtained from First Chicago Investment Advisors. The ICM index consists of nine asset classes-large cap equity, small cap equity, international equity, venture capital, domestic bonds, international bonds, nondollar bonds, cash equivalents, and commercial properties-with the commercial nonfarm real estate component based on appraised values from properties in a CREF portfolio. The sum of the asset submarkets does not represent the "true" U.S. market portfolio since assets such as human capital and consumer durables are omitted. A possibility also exists that some assets are overstated. ${ }^{7}$ Despite these shortcomings, the asset classes included do comprise the most liquid and identifiable components of investable capital wealth. The study consequently assumes that the asset categories chosen are a reasonable representation of the investment marketplace.

Table 2 reports the descriptive statistics for the six overall market indices and the two real estate market proxies. This table reveals that the standard deviation of the return on the market proxy decreases as one or more types of real estate are introduced into the index and also as stocks receive less weight. In addition to this, table 2 shows that the return on both the FRC and ACLI real estate indices are uncorrelated with the return on any of the overall market proxies. The only exception to this is the correlation of the value-weighted ACLI index with the USMI1 index. This is expected since the ACLI index is a component of the USMI1 index but not other market proxy. However, this correlation is only 
marginally significant from zero at the 5 percent level of significance. Another feature of table 2 is that the correlation among the overall market indices is high and is consistent with the dominant effect of the variability in stock returns in general. Table 2 also displays statistics associated with the first four autocorrelations of the returns on each of the six overall market proxies and the two real estate market portfolios. Table 2 reveals that the first four sample autocorrelations of the returns on the market indices are close to zero at all lags in general. The only exception to this is the FRC return series which exhibits fourth order autocorrelation. This autocorrelation arises in part since the outside appraisals for the properties in most CREFs are done only once a year in the fourth quarter with in house appraisals performed on CREF properties for the other three quarters.

Table 1. Market weights for U.S. market proxy (USMIl and USMI2)

\begin{tabular}{|c|c|c|c|c|c|c|}
\hline Quarter & Stocks & Bonds & Cash & Commercial R.E. & Farms & Homes \\
\hline $1978 Q 2$ & .2200 & .1200 & .0637 & .1600 & .1200 & .3100 \\
\hline 1978Q3 & .2300 & .1200 & .0612 & .1600 & .1200 & .3100 \\
\hline 1978Q4 & .2100 & .1100 & .0637 & .1700 & .1300 & .3200 \\
\hline 1979Q1 & .2200 & .1100 & .0632 & .1700 & .1300 & .3200 \\
\hline 1979Q2 & .2200 & .1100 & .0626 & .1700 & .1300 & .3200 \\
\hline 1979Q3 & .2200 & .1100 & .0627 & .1700 & .1300 & .3200 \\
\hline $1979 Q 4$ & .2100 & .1000 & .0651 & .1700 & .1300 & .3200 \\
\hline 1980Q1 & .2000 & .0932 & .0693 & .1800 & .1300 & .3300 \\
\hline 1980Q2 & .2200 & .1000 & .0653 & .1700 & .1200 & .3100 \\
\hline 1980Q3 & .2300 & .1000 & .0655 & .1700 & .1200 & .3100 \\
\hline 1980Q4 & .2400 & .0947 & .0662 & .1700 & .1200 & .3100 \\
\hline 1981Q1 & .2300 & .0895 & .0701 & .1800 & .1200 & .3100 \\
\hline 1981Q2 & .2200 & .0943 & .0692 & .1800 & .1200 & .3100 \\
\hline 1981Q3 & .2000 & .0921 & .0735 & .1900 & .1200 & .3200 \\
\hline 1981Q4 & .2000 & .1000 & .0743 & .1900 & .1100 & .3200 \\
\hline 1982Q1 & .1900 & .1000 & .0779 & .1900 & .1200 & .3200 \\
\hline 1982Q2 & .1800 & .1100 & .0808 & .2000 & .1200 & .3100 \\
\hline 1982Q3 & .2000 & .1200 & .0808 & .1900 & .1100 & .3000 \\
\hline 1982Q4 & .2200 & .1300 & .0821 & .1800 & .1000 & .2800 \\
\hline 1983Q1 & .2300 & .1400 & .0802 & .1800 & .1000 & .2800 \\
\hline 1983Q2 & .2500 & .1300 & .0771 & .1700 & .0920 & .2700 \\
\hline 1983Q3 & .2400 & .1400 & .0779 & .1700 & .0910 & .2800 \\
\hline $1983 Q 4$ & .2400 & .1400 & .0783 & .1700 & .0880 & .2800 \\
\hline 1984Q1 & .2300 & .1400 & .0811 & .1800 & .0890 & .2800 \\
\hline 1984Q2 & .2200 & .1400 & .0842 & .1800 & .0860 & .2900 \\
\hline 1984Q3 & .2300 & .1500 & .0836 & .1800 & .0790 & .2800 \\
\hline $1984 Q 4$ & .2300 & .1600 & .0859 & .1800 & .0750 & .2800 \\
\hline 1985Q1 & .2400 & .1600 & .0850 & .1700 & .0700 & .2700 \\
\hline 1985Q2 & .2500 & .1700 & .0827 & .1700 & .0650 & .2600 \\
\hline 1985Q3 & .2600 & .1700 & .0848 & .1700 & .0620 & .2600 \\
\hline 1985Q4 & .2800 & .1800 & .0847 & .1600 & .0570 & .2400 \\
\hline 1986Q1 & .2800 & .1900 & .0813 & .1600 & .0530 & .2400 \\
\hline 1986Q2 & .2900 & .1900 & .0801 & .1500 & .0500 & .2400 \\
\hline 1986Q3 & .2700 & .2000 & .0839 & .1600 & .0480 & .2400 \\
\hline
\end{tabular}

Note: The weight shown for stocks includes stocks of small capitalized firms in addition to large, well-capitalized firms. 
Table 2. Statistical properties of the excess returns on the overall market proxies and commercial real estate market indices

\begin{tabular}{|c|c|c|c|c|c|c|c|c|c|c|c|c|c|c|}
\hline \multirow[b]{2}{*}{ Proxy } & \multirow[b]{2}{*}{ Mean } & \multirow[b]{2}{*}{ Stdev } & \multicolumn{4}{|c|}{ Autocorrelations ${ }^{a}$} & \multicolumn{8}{|c|}{ Correlations $^{\mathrm{b}}$} \\
\hline & & & $\rho_{1}$ & $\rho_{2}$ & $\rho_{3}$ & $\rho_{4}$ & SP500 & MGCI & SMI & USMII & USMI2 & ICM & ACLI & FRC \\
\hline SP500 & .018 & .070 & .11 & .07 & .07 & .05 & 1.00 & & & & & & & \\
\hline MGCI & .009 & .080 & .12 & .05 & .11 & .19 & .81 & 1.00 & & & & & & \\
\hline SMI & .007 & .053 & .08 & .06 & .05 & .20 & .82 & .97 & 1.00 & & & & & \\
\hline USMIl & .013 & .032 & .03 & .00 & .07 & .07 & .73 & .85 & .86 & 1.00 & & & & \\
\hline USML2 & .006 & .027 & .13 & .01 & .14 & .04 & .78 & .94 & .91 & .92 & 1.00 & & & \\
\hline ICM & .010 & .053 & .09 & .06 & .09 & .02 & .78 & .85 & .92 & .77 & .84 & 1.00 & & \\
\hline VWACLI & .037 & .067 & .08 & .04 & .15 & .07 & .09 & .03 & .08 & .36 & .05 & .02 & 1.00 & \\
\hline VWFRC & .009 & .012 & .20 & .16 & .11 & .43 & .06 & -.01 & -.07 & -.08 & .05 & .01 & -.14 & 1.00 \\
\hline
\end{tabular}

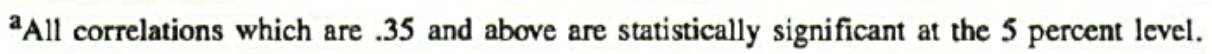

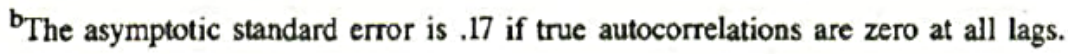

\section{Methodology}

The Jorion and Schwartz tests for Inter-Asset Market Segmentation vs. Integration

The Jorion and Schwartz (1986) framework is used to test whether the commercial real estate market is integrated with or segmented from the stock market. The test for integration involves a determination of whether a premium $\gamma_{2}$ is associated with the conditional commercial real estate market risk $\beta_{i C \mid M}$. The existence of the $\gamma_{2}$ premium represents an additional premium over and above the systematic risk premium $\gamma_{1}$ associated with the overall market portfolio. The conditional commercial real estate market risk is defined as the risk associated with the return on the commercial real estate market portfolio which is independent of the return on the overall market index $M$. This orthogonal return alternatively represents the return on the commercial real estate market portfolio, holding constant any influence on the overall market index $M$, and is denoted as $\tilde{v}_{C \mid M}$. The CAPM used to test for integration is, therefore,

(1)

$E\left(\tilde{R}_{i}\right)=\gamma_{0}+\gamma_{1} \beta_{i M}+\gamma_{2} \beta_{i C \mid M}$

where $R^{2}$ is the nominal return on asset $i$ in excess of the risk-free rate. Since the Sharpe-Lintner version or the Black version of the CAPM is

(2)

$E\left(\tilde{R}_{i}\right)=\gamma_{0}+\gamma_{1} \beta_{i M}$, 
this implies that equation (1) is consistent with the traditional (or Black) CAPM in equation (2) only if $\gamma_{2}=0$. Integration thus obtains if no $\gamma_{2}$ premium is associated with the commercial real estate market risk $\left(\gamma_{2}=0\right)$, while segmentation is supported if a super risk premium exists $\left(\gamma_{2}>0\right)$.

The test for segmentation is similar in nature to the test for integration. If the commercial real estate market is segmented from the stock market, then the only risk that should matter is the systematic risk $\left(\beta_{i C}\right)$ associated with the return on the commercial real estate market $\left(\tilde{R}_{C}\right)$. Consequently, the CAPM which should hold with respect to commercial properties if the commercial real estate market is completely segmented from the stock market is:

$$
E\left(\tilde{R}_{i}\right)=\delta_{0}+\delta_{1} \beta_{i C}
$$

Equation (3) can be rewritten as

$$
E\left(\tilde{R}_{i}\right)=\delta_{0}+\delta_{1} \beta_{i C}+\delta_{2} \beta_{i M \mid C}
$$

where $\delta_{2}$ is the premium associated with the conditional overall market risk $\beta_{i M \mid C}$. The conditional overall market risk is defined as the risk associated with the portion of the overall market return which is orthogonal to the return on the commercial real estate market proxy. This orthogonal return is denoted as $\tilde{v}_{M \mid C}$. Since equation (3) is the correct pricing paradigm for commercial real estate given segmentation, segmentation is present with respect to equation (4) if no $\delta_{2}$ premium is associated with the conditional overall market risk $\left(\delta_{2}=0\right)$ while integration is supported if the "pure" overall market risk factor $\beta_{i M \mid C}$ is priced $\left(\delta_{2}>0\right)$.

To develop an empirical test for integration, we assume that the excess rate of return on the commercial real estate market portfolio $\widetilde{R}_{C}$ is separable into a component that is perfectly correlated with the excess rate of return on the overall market portfolio $\tilde{R}_{M}$ and a component $\tilde{v}_{C \mid M}$ which is not correlated with $\widetilde{R}_{M}$.

(5)

$$
\tilde{R}_{C}=\alpha_{C M}+\beta_{C M} \tilde{R}_{M}+\tilde{v}_{C \mid M}
$$

where $E\left(\tilde{v}_{C \mid M}\right)=\operatorname{cov}\left(\tilde{v}_{C \mid M}, \tilde{R}_{M}\right)$ by construction. In addition to this, the rate of return on the ith asset is decomposed into three parts. The first component is perfectly correlated with the rate of return on 
the overall market portfolio. The second component is perfectly correlated with $\tilde{v}_{C \mid M}$ while the third component $\tilde{e}_{i t}$ is not correlated with either $\tilde{R}_{M}$ or $\tilde{v}_{C \mid M}$.

(6)

$$
\tilde{R}_{i t}=\alpha_{1}+\beta_{i M} \tilde{R}_{M t}+\beta_{i C \mid M} \tilde{v}_{C \mid M}+\tilde{e}_{i t}
$$

where $\alpha_{i}=E\left(\tilde{R}_{i t}\right)-\beta_{i M} E\left(\tilde{R}_{M t}\right), \beta_{i M}=\frac{\operatorname{cov}\left(\tilde{R}_{i t}, \tilde{R}_{M t}\right)}{\operatorname{var}\left(\tilde{R}_{M t}\right)}, \beta_{i C \mid M}=\frac{\operatorname{cov}\left(\tilde{R}_{i t}, \tilde{v}_{C \mid M}\right)}{\operatorname{var}\left(\tilde{v}_{C \mid M}\right)}$ and by construction

$E\left(\tilde{e}_{i t}\right)=\operatorname{cov}\left(\tilde{e}_{i t}, \tilde{R}_{M t}\right)=\operatorname{cov}\left(\tilde{e}_{i t}, \tilde{v}_{C \mid M}\right)=\operatorname{cov}\left(\tilde{e}_{i t}, R_{C t}\right)=0$. Equation (6) is equivalent to

$$
\left.\tilde{R}_{i t}=E\left(\tilde{R}_{i t}\right)+\beta_{i M}\left[\tilde{R}_{M t}\right)-E\left(\tilde{R}_{M t}\right)\right]+\beta_{i C \mid M} \tilde{v}_{C \mid M}+\tilde{e}_{i t}
$$

If we assume rational expectations, then we can substitute equation (1) into equation (7) to obtain the following model which Jorion and Schwartz (1986) use to test whether integration exists: ${ }^{8}$

$$
\tilde{R}_{i t}=\gamma_{0}\left(1-\beta_{i M}\right)+\gamma_{2} \beta_{i C \mid M}+\beta_{i M} \tilde{R}_{M t}+\beta_{i C \mid M} \tilde{v}_{C \mid M t}+\tilde{e}_{i t}
$$

Using a similar logic process, the applicable model for the test of segmentation is

$$
\tilde{R}_{i t}=\delta_{0}\left(1-\beta_{i C}\right)+\delta_{2} \beta_{i M \mid C}+\beta_{i C} \tilde{R}_{C t}+\beta_{i M \mid C} \tilde{v}_{M \mid C t}+\tilde{e}_{i t}
$$

\section{The Test Procedure}

The current study does not use the two-step estimation procedure set forth in Jorion and Schwartz (1986) since the residual $\tilde{v}_{C \mid M}$ from equation (5), which is used as an independent variable in equation (8), cannot be measured without error. Econometric problems that arise when generated residuals are used as regressors in a regression equation include the feet that the two-step procedure yields consistent but inefficient parameter estimates with inconsistent estimates of the standard errors of the parameters. Pagan (1984) shows that the estimated standard errors are understated since the variance-covariance matrix of errors is not spherical. This in turn biases not only the F-statistic but also the T statistics and results in a tendency to reject the null hypothesis too often.

To rectify the problems associated with the Jorion and Schwartz two-step procedure, the return on the commercial real estate market portfolio in excess of its expected return $\left[\tilde{R}_{i t}-E\left(\tilde{R}_{C t}\right)\right]$ is 
substituted for $\tilde{v}_{C \mid M t}$. Recall that $\tilde{v}_{C \mid M t}$ represents the rate-of-return component of the commercial real estate market portfolio which is uncorrelated with the rate of return on the overall market portfolio in equation (8). In a similar fashion, $\left[\widetilde{R}_{M t}-E\left(\widetilde{R}_{M t}\right)\right]$ is used in lieu of $\tilde{v}_{M \mid C t}$ in equation (9). The substitution of $\left[\tilde{R}_{C t}-E\left(\tilde{R}_{C t}\right)\right]$ for $\tilde{v}_{C \mid M t}$ and $\left[\tilde{R}_{M t}-E\left(\tilde{R}_{M t}\right)\right]$ for $\tilde{v}_{M \mid C t}$ is justified in the current study since table 2 reveals that no statistically significant collinearity exists between either the value-weighted commercial real estate market index (VWFRC and VWACLI) and any of the six overall market indices. ${ }^{9}$ This contrasts with the Jorion and Schwartz (1986) study in which collinearity is a problem, and therefore the isolation of $\tilde{v}_{C \mid M t}$ for the test of integration and the isolation of $\tilde{v}_{M \mid C t}$ for the test of segmentation by a projection is necessary. Collinearity is not a problem in the current study since none of the overall market indices except the USMI and ICM has any real estate component. Even though real estate in aggregate comprises over 50 percent of the USMI portfolio, no property type is highly correlated with each other or with stocks or bonds. The proportion of the ICM portfolio comprised by commercial real estate is also not more than 20 percent.

Since table 2 reveals that the correlation between the rate of return on either commercial real estate market proxy and the overall market portfolio is not statistically significant from zero $\left(\rho_{C M}=0\right)$, it follows from equation (5) that

$$
\begin{aligned}
\tilde{v}_{C \mid M} & =\tilde{R}_{C}-\alpha_{C M}-\beta_{C M} \tilde{R}_{M} \\
& =\tilde{R}_{C}-\left[E\left(\tilde{R}_{C}\right)-\rho_{C M}\left(\frac{\sigma_{C}}{\sigma_{M}}\right) E\left(\tilde{R}_{M}\right)\right]-\rho_{C M}\left(\frac{\sigma_{C}}{\sigma_{M}}\right) \tilde{R}_{M} \\
& =\tilde{R}_{C}-E\left(\tilde{R}_{C}\right) \text { if } \rho_{C M}=0 .
\end{aligned}
$$

Also,

$$
\beta_{i C}=\beta_{i C \mid M} \text { and } \beta_{i M}=\beta_{i M \mid C} \quad \text { if } \rho_{C M}=0 .
$$

Substitution of the preceding results into equation (7) yields

$$
\tilde{R}_{i t}=E\left(\tilde{R}_{i t}\right)+\beta_{i M}\left[\tilde{R}_{M t}-E\left(\tilde{R}_{M t}\right)\right]+\beta_{i C}\left[\tilde{R}_{C t}-E\left(\tilde{R}_{C t}\right)\right]+\tilde{e}_{i t}
$$

If equation (1) is next substituted into equation (12), given rational expectations, then the following model obtains which is used to test whether integration exists: 
(13)

$$
\tilde{R}_{i t}=\gamma_{0}\left(1-\beta_{i M}\right)+\gamma_{2} \beta_{i C}+\beta_{i M} \tilde{R}_{M t}+\beta_{i C}\left[\tilde{R}_{C t}-E\left(\tilde{R}_{C t}\right)\right]+\tilde{e}_{i t}
$$

Using a similar logic process, the applicable model for the test of segmentation is

$$
\tilde{R}_{i t}=\delta_{0}\left(1-\beta_{i C}\right)+\delta_{2} \beta_{i M}+\beta_{i C} \tilde{R}_{C t}+\beta_{i M}\left[\tilde{R}_{M t}-E\left(\tilde{R}_{M t}\right)\right]+\tilde{e}_{i t} .
$$

The model in equation (13) represents a constrained version of the following unrestricted model which obtains from substituting the results of equation (10) and equation (11) into equation (6):

$$
\tilde{R}_{i t}=\alpha_{i}+\beta_{i M} \tilde{R}_{M t}+\beta_{i C}\left[\tilde{R}_{C t}-E\left(\tilde{R}_{C t}\right)\right]+\tilde{e}_{i t}
$$

where the constraint in equation (13) is on the intercept term in equation (15)

$$
\alpha_{i}=\gamma_{0}\left(1-\beta_{i M}\right)+\gamma_{2} \beta_{i C} \quad \text { for all } i \quad i=1, \ldots, N \text {. }
$$

This nonlinear cross-sectional restriction on a system of $N$ regression equations is the basis for the subsequent test of integration. Similarly, the model in equation (14) represents the constrained version of the following unconstrained model:

$$
\tilde{R}_{i t}=\alpha_{i}+\beta_{i C} \tilde{R}_{C t}+\beta_{i M}\left[\tilde{R}_{M t}-E\left(\tilde{R}_{M t}\right)\right]+\tilde{e}_{i t}
$$

where the restriction associated with equation (14) is on the intercept term in equation (17)

$$
\alpha_{i}=\delta_{0}\left(1-\beta_{i C}\right)+\delta_{2} \beta_{i M} \quad \text { for all } i \quad i=1, \ldots, N .
$$

A system of nonlinear, iterative seemingly unrelated regressions (NLITSUR) with a correction for autocorrelation is used to estimate jointly the parameters for the test of integration and the test of segmentation, respectively. This estimation approach which is discussed in Gallant (1975) and Gibbons (1982) involves maximizing the restricted and unrestricted likelihoods using a one-step Gauss-Newton procedure. A likelihood ratio test (LRT) with a Jobson and Korkie (1982) correction for small sample sizes 
is used to compare the statistical fit of the unrestricted model with that of the restricted model. ${ }^{10}$ Model estimation proceeds after the number of assets is first reduced to a smaller number of portfolios to avoid a singular covariance matrix of residuals since the number of assets exceeds the number of time periods. Portfolios are also used instead of return observations on individual properties given prior evidence that the risk characteristics associated with portfolios arc relatively more stationary over time relative to that for individual properties.

Nine mutually exclusive portfolios are constructed to test the model. For the test of integration, assets are classified into portfolios with respect to their betas on the overall market index and the commercial nonfarm real estate market proxy. Two sets of portfolios are constructed. The first set consists of assets grouped into three portfolios in terms of their overall market betas $\left(\beta_{i M}\right)$. Each portfolio is next subdivided into three portfolios based on the commercial real estate market betas $\left(\beta_{i C}\right)$. The portfolio formation process is reversed for the second set of portfolios. This procedure is repeated with respect to commercial properties and equity REITs. ${ }^{11}$ Equally weighted portfolios are constructed after the assets are categorized into groups with the return computed for each portfolio. The return series for each equally weighted portfolio formed is tested for the autocorrelation of a series. A similar procedure is followed with respect to the test for segmented markets.

Two sets of commercial real estate are used in testing whether the nonresidential real estate market is segmented from the stock market. The two sets are FRC properties and ACLI properties. Appraised values underlie the returns on FRC real estate while imputed sale prices are associated with the $A C L I$ returns. A separate evaluation of FRC and $A C L I$ properties is undertaken to inquire whether the use of appraisals in lieu of sales prices leads to an erroneous conclusion that market segmentation exists. Six overall market proxies are also used to investigate the impact of the omitted asset phenomenon. The omitted asset phenomenon could account for any premium associated with market segmentation if this premium diminishes as more asset types are included in the overall market portfolio.

\section{Testable Hypotheses}

The Jorion-Schwartz (J-S) model allows one to distinguish whether segmentation arises from indirect barriers or legal barriers. Indirect barriers include but are not limited to asymmetric information obstacles, differences in the quantity and quality of financial reporting, and the high cost associated with the investment which arise from the lumpy asset nature of real estate and limited marketability. Legal constraints in contrast arise from institutional investors having a different legal status relative to 
individual investors such as restrictions on the ownership of certain asset classes. The determination of which constraint is the prime catalyst in segmentation involves the use of interlisted assets. Equity REITs are assumed to resemble interlisted securities since these assets possess both real estate and stock characteristics. ${ }^{12}$ If indirect constraints are the only source of segmentation, then one would expect that equity REITs are integrated while commercial nonfarm real estate is segmented from the stock market. Barriers are of the legal type in contrast if both equity REITs and commercial real estate are segmented from the stock market. This suggests the following hypotheses for the existence of segmentation given equation (13):

$\mathbf{H}_{0}$ : The commercial real estate market is integrated $\left(\gamma_{2 I}=0\right.$ and $\left.\gamma_{2 C}=0\right)$

$\mathbf{H}_{\mathrm{A} 1}$ : Commercial real estate market is segmented due to legal constraints $\left(\gamma_{2 I}>0\right.$ and $\left.\gamma_{2 C}>0\right)$ $\mathbf{H}_{\mathrm{A} 2}$ : Commercial real estate market is segmented due to indirect constraints $\left(\gamma_{2 I}=0\right.$ and $\left.\gamma_{2 C}>0\right)$ where the subscript / denotes interlisted equity REITs and the subscript $C$ stands for commercial real estate. If equation (14) is used, then the hypotheses for the existence of integration are as follows: $\mathbf{H}_{01}$ : Commercial real estate market is segmented due to legal constraints $\left(\delta_{2 I}=0\right.$ and $\delta_{2 C}=0$ ) $\mathbf{H}_{02}$ : Commercial real estate market is segmented due to indirect constraints $\left(\delta_{2 I}>0\right.$ and $\left.\delta_{2 C}=0\right)$ $\mathbf{H}_{\mathrm{A}}$ : The commercial real estate market is integrated $\left(\delta_{2 I}>0\right.$ and $\left.\delta_{2 C}>0\right)$

Another hypothesis tested involves whether the Sharpe-Lintner or Black form of the CAPM holds if markets are integrated. This test of the Sharpe-Lintner CAPM versus the Black version of the CAPM is not central to the issue of whether the commercial real estate market is segmented from or integrated with the stock market. The Sharpe-Lintner version obtains if $\gamma_{0}=0$. A nonzero $\gamma_{0} \neq 0$ in contrast implies that the Black model holds. Formally,

$\mathbf{H}_{0}$ : The Sharpe-Lintner version of the CAPM holds $\left(\gamma_{0}=0\right)$

$\mathbf{H}_{\mathrm{A}}$ : The Black version of the CAPM holds $\left(\gamma_{0} \neq 0\right)$.

\section{Empirical Results}

\section{Results Using FRC Data}

Table 3 presents the results for the test of integration with respect to FRC data over the 1978 to 1986 period using six different market indices. In general, the results are consistent with the hypothesis that the commercial real estate market is segmented from the stock market as a result of indirect 
constraints. A significantly positive super risk premium 72 is associated with the commercial real estate market risk $0 c$ at the 5 percent level of significance regardless of which market index and grouping procedure are used. In contrast, no super risk premium is associated with equity REITS at the 5 percent level of significance. Equity REITs are therefore integrated with the stock market even though the commercial real estate that underlies the equity REITs is segmented from the stock market. The only exception to this general result is when the test for integration is conducted using the SMI proxy. In this case, segmentation arises as the result of legal constraints since both commercial properties and equity REITs are segmented from the stock market. The finding that legal constraints are the primary segmentation catalyst conflicts with what one would expect a priori since investors are not constrained from holding equity REITs although security laws limit the proportion of a REIT that any set of five investors can own. ${ }^{13}$ On the other hand, segmentation due to indirect constraints is more plausible ex ante since information on real estate prices and cash flows are usually proprietary. Even in states such as California where prices are a matter of public record, a seller can disguise the true price paid for the property through purchasing extra conveyance stamps. These stamps are used to compute the price paid for a property.

Another distinguishing feature of table 3 is that the USMI2 index has the lowest super risk premium as expected given the implication of Roll (1977). However, $\gamma_{2}$ does not necessarily diminish as more assets are included in the portfolio. For example, the super risk premium associated with the SP500 is less than that for the ICM index. 
Table 3. Tests of integration using FRC data

\begin{tabular}{|c|c|c|c|c|c|c|c|}
\hline \multicolumn{8}{|l|}{ All FRC and EREITs } \\
\hline Son Procedure & $\gamma_{0}$ & $\mathbf{T}\left(\gamma_{0}\right)$ & PROB & $\gamma_{2}$ & $\mathrm{~T}\left(\gamma_{2}\right)$ & PROB & $x_{i}^{2}$ \\
\hline SP500/VWFRC & .0051 & 3.77 & .00 & .0100 & 6.10 & .00 & 5.765 \\
\hline MGCIVWFRC & .0026 & 1.46 & .15 & .0107 & 4.73 & .00 & 5.767 \\
\hline SMI/VWFRC & .0001 & 0.06 & .95 & .0133 & 5.78 & .00 & 5.765 \\
\hline USMII/VWFRC & .0015 & 0.79 & .44 & .0115 & 5.36 & .00 & 5.765 \\
\hline USMI2/VWFRC & .0006 & 0.38 & .71 & .0119 & 5.15 & .00 & 5.763 \\
\hline ICM/VWFRC & .0006 & 0.28 & .78 & .0136 & 5.89 & .00 & 5.765 \\
\hline VWFRC/SP500 & .0047 & 3.54 & .00 & .0068 & 4.17 & .00 & 5.765 \\
\hline VWFRC/MGCI & .0001 & 0.05 & .96 & .0143 & 5.80 & .00 & 5.764 \\
\hline VWFRC/SMI & .0048 & 2.88 & .01 & .0091 & 5.02 & .00 & 5.765 \\
\hline VWFRC/USMII & .0032 & 2.04 & .05 & .0094 & 5.03 & .00 & 5.764 \\
\hline VWFRC/USMI2 & .0011 & 0.66 & .51 & .0110 & 5.35 & .00 & 5.764 \\
\hline VWFRC/ICM & .0010 & 0.55 & .59 & .0111 & 4.56 & .00 & 5.765 \\
\hline \multicolumn{8}{|l|}{ FRC Properties } \\
\hline Sort Procedure & $\gamma_{0}$ & $\mathbf{T}\left(\gamma_{0}\right)$ & PROB & $\gamma_{2}$ & $\mathbf{T}\left(\gamma_{2}\right)$ & PROB & $x_{i}^{2}$ \\
\hline SP500/VWFRC & -.0039 & -1.73 & .09 & .0160 & 5.19 & .00 & 5.767 \\
\hline MGCI/VWFRC & -.0010 & -.42 & .67 & .0119 & 5.10 & .00 & 5.764 \\
\hline SMI/VWFRC & -.0059 & -2.00 & .05 & .0180 & 5.28 & .00 & 5.761 \\
\hline USMI/VWFRC & -.0020 & -.83 & .41 & .0128 & 4.91 & .00 & 5.764 \\
\hline USMI 2 /VWFRC & -.0004 & -.18 & .86 & .0110 & 5.01 & .00 & 5.763 \\
\hline ICM/VWFRC & -.0081 & -2.82 & .01 & .0194 & 5.68 & .00 & 5.765 \\
\hline VWFRC/SP500 & -.0009 & -.50 & .62 & .0114 & 5.73 & .00 & 5.771 \\
\hline VWFRC/MGCI & -.0002 & -.13 & .90 & .0110 & 6.09 & .00 & 5.765 \\
\hline VWFRC/SMI & .0000 & .03 & .98 & .0111 & 5.31 & .00 & 5.761 \\
\hline VWFRC/USMII & -.0026 & -1.00 & .32 & .0137 & 4.83 & .00 & 5.764 \\
\hline VWFRC/USMI2 & -.0011 & -.60 & .55 & .0108 & 5.37 & .00 & 5.767 \\
\hline VWFRC/ICM & -.0010 & -.58 & .57 & .0122 & 5.52 & .00 & 5.762 \\
\hline \multicolumn{8}{|l|}{ Equity REITs } \\
\hline Sort Procedure & $\gamma_{0}$ & $\mathrm{~T}\left(\gamma_{0}\right)$ & PROB & $\gamma_{2}$ & $\mathrm{~T}\left(\gamma_{2}\right)$ & PROB & $x_{1}^{2}$ \\
\hline SP500/VWFRC & .0329 & 4.09 & .00 & .0015 & 0.75 & .46 & 5.765 \\
\hline MGCI/VWFRC & .0426 & 6.36 & .00 & .0041 & 1.94 & .06 & 5.765 \\
\hline SMLVWFRC & .0480 & 2.47 & .02 & .0234 & 2.70 & .01 & 5.765 \\
\hline USMII/VWFRC & -.0006 & -.91 & .37 & -.0046 & -1.77 & .09 & 5.765 \\
\hline USMI2/VWFRC & -.0299 & -2.66 & .01 & -.0072 & -1.77 & .09 & 5.764 \\
\hline ICM/VWFRC & .0215 & 2.93 & .01 & .0006 & 0.26 & .80 & 5.765 \\
\hline VWFRC/SP500 & .0235 & 2.78 & .01 & -.0059 & -2.75 & .01 & 5.765 \\
\hline VWFRC/MGCI & .0458 & 6.61 & .00 & .0022 & 1.02 & .32 & 5.764 \\
\hline VWFRC/SMI & .0965 & 2.64 & .01 & .0252 & 2.12 & .04 & 5.765 \\
\hline VWFRC/USMII & -.0257 & -1.65 & .11 & -.0108 & -2.19 & .04 & 5.764 \\
\hline VWFRC/USMI2 & -.0333 & -2.09 & .04 & -0.156 & -2.65 & .01 & 5.764 \\
\hline VWFRC/ICM & .0312 & 3.94 & .00 & .0008 & 0.38 & .71 & 5.765 \\
\hline
\end{tabular}

Note: The PROB is the two-tailed probability that the associated coefficient is not significantly different from zero.

The last column in table 3 reveals that the two-factor model for integration given in equation (13) is consistent with the data across all market indices and sorting procedures. An insignificant chi- 
square test statistic evidences this finding. This statistic tests the cross-sectional restriction given in equation (16) on the intercept term in equation (15).

Table 4 presents the test of segmentation for the FRC data. The results of this table complement those of table 3 . In the test of segmentation, we expect to find $\delta_{2}$ significantly positive if integration occurs since this implies that a positive relationship exists between expected returns for real estate and the overall market factor. Table 4 shows that this positive relationship is present in the case of equity REITs with respect to all market proxies at the 5 percent level of significance. However, the premium $\delta_{2}$ is significantly negative for FRC commercial properties across sorting and portfolios. This evidence is consistent with the hypothesis that indirect barriers such as the cost and quality of information are responsible for market segmentation. The chi-square statistic in the last column of table 4 reveals that the two-factor segmentation model in equation (14), like the two-factor model for integration in equation (13), is consistent with the data.

\subsection{Results Using ACLI Data}

The results for the test of integration using ACLI data in table 5 contrast with the findings based on table 3 when FRC data are employed. Table 5 reveals that the commercial real estate market is integrated with the stock market regardless of the market proxy chosen when a 5 percent level of significance is used. One plausible explanation for this finding is that the ACU data arc not based on appraised values in contrast to the FRC data. However, some evidence of segmentation due to indirect barriers exists with respect to the USMI 2 proxy if a 10 percent rather than a 5 percent significance level is chosen.

Another distinctive feature of table 5 when compared to table 3 is that the USMI2 has the largest super risk premium $\left(\gamma_{2}\right)$ relative to all other indices across sorting procedures when the ACLI properties are analyzed. This finding contrasts with the USMI2 index in table 3 which has the lowest $\gamma_{2}$ with respect to the FRC data. Table 5 also reveals, when compared to table 3 , that the super risk premium increases rather than decreases in general as more assets are included in the market proxy given the SP500 as the benchmark portfolio. Unlike table 3, however, none of the $\gamma_{2}$ premiums is significantly different from zero at the 5 percent significance level.

The findings in table 6 for the tests of segmentation using ACLI properties do not support the evidence for integration presented in table 4. Table 6 reveals that the commercial real estate market is segmented from the stock market either as the result of indirect constraints or legal constraints. Which investment barrier acts as the prime segmentation catalyst depends on which market proxy and sorting 
procedure is used. Market proxies that support legal constraints as the prime segmentation catalyst include the SP500, USMI1, and USMI2 across all grouping procedures. Legal constraints as the prime segmentation catalyst is also consistent with the MGCIA^ACLI and VWACLI/SMI sorting scheme. Segmentation arising from indirect constraints is consistent with all other scenarios. Among these scenarios is the ICM market proxy sorted first with respect to the beta on the ICM and then with respect to the VWACU (ICM/VWACLI) at the 5 percent level of significance and the converse VWACLI/ICM sorting scheme at the 10 percent level of significance. Although the prime catalyst responsible for segmentation varies with the market proxy and sorting scheme chosen, one should note that the $\delta_{2}$ premium is positive for equity REITs across all classification procedures. Further, the $\delta_{2}$ premium is significant in most cases for equity REITs and the 20 percent level which suggests that there is weak evidence at this level in support of market segmentation due to indirect constraints. 
Table 4. Tests of segmentation using FRC data

\begin{tabular}{|c|c|c|c|c|c|c|c|}
\hline \multicolumn{8}{|l|}{ All FRC and EREITs } \\
\hline Sort Procedure & $\delta_{0}$ & $\mathrm{~T}\left(\delta_{0}\right)$ & PROB & $\delta_{2}$ & $\mathrm{~T}\left(\delta_{2}\right)$ & PROB & $x_{0}^{2}$ \\
\hline SP500/VWFRC & .0023 & 1.15 & .26 & .0756 & 5.15 & .00 & 5.764 \\
\hline MGCI/VWFRC & .0014 & 0.68 & .50 & .0581 & 4.48 & .00 & 5.765 \\
\hline SMI/VWFRC & -.0034 & -1.03 & .31 & .0571 & 3.55 & .00 & 5.764 \\
\hline USMIIVWWRC & .0018 & 0.95 & .35 & .0245 & 4.03 & .00 & 5.763 \\
\hline USMI2/VWFRC & .0031 & 2.20 & .04 & .0211 & 4.33 &.$\infty$ & 5.758 \\
\hline ICM/VWFRC & -.0068 & -1.44 & .16 & .0787 & 2.90 & .01 & 5.765 \\
\hline VWFRC/SP500 & .0057 & 5.21 & .00 & .0395 & 4.05 & .00 & 5.767 \\
\hline VWFRC/MGCI & .0008 & 0.54 & .59 & .0794 & 4.80 & .00 & 5.764 \\
\hline VWFRC/SMI & .0059 & 5.37 & .00 & .0226 & 4.16 & .00 & 5.765 \\
\hline VWFRC/USMII & .0040 & 3.15 & .00 & .0223 & 4.02 & .00 & 4.764 \\
\hline VWFRC/USMI2 & .0033 & 2.52 & .02 & .0190 & 4.41 & .00 & 5.764 \\
\hline VWFRC/ICM & .0026 & 1.92 & .06 & .0284 & 2.86 & .01 & 5.763 \\
\hline \multicolumn{8}{|l|}{ FRC Properties } \\
\hline Son Procedure & $\delta_{0}$ & $\mathbf{T}\left(\delta_{0}\right)$ & PROB & $\delta_{2}$ & $\mathrm{~T}\left(\delta_{2}\right)$ & PROB & $x_{i}^{2}$ \\
\hline SP500/VWFRC & .0044 & 3.04 & .00 & -.0822 & -3.77 & .00 & 5.766 \\
\hline MGCI/VWFRC & .0062 & 4.30 & .00 & -.0752 & -3.92 & .00 & 5.763 \\
\hline SMI/VWFRC & .0033 & 2.60 & .01 & -.0498 & -4.91 & .00 & 5.764 \\
\hline USMI/VWFRC & .0040 & 2.72 & .01 & -.0228 & -4.01 & .00 & 5.758 \\
\hline USMI2/VWFRC & .0034 & 1.84 & .07 & -.0334 & -3.18 & .00 & 5.765 \\
\hline ICM/VWFRC & .0041 & 2.91 & .01 & -.0469 & -4.66 & .00 & 5.764 \\
\hline VWFRC/SP500 & .0062 & 4.27 & .00 & -.0849 & -3.51 & .00 & 5.765 \\
\hline VWFRC/MGCI & .0032 & 2.78 & .01 & -.0592 & -3.53 & .00 & 5.764 \\
\hline VWFRC/SMI & .0033 & 2.89 & .01 & -.0432 & -3.87 & .00 & 5.761 \\
\hline VWFRC/USMII & .0040 & 2.78 & .01 & -.0251 & -3.88 &.$\infty$ & 5.764 \\
\hline VWFRC/USMI2 & .0030 & 2.60 & .01 & -.0189 & -4.04 & .00 & 5.763 \\
\hline VWFRC/ICM & .0039 & 3.24 & .00 & -.0392 & -3.61 &.$\infty$ & 5.761 \\
\hline \multicolumn{8}{|l|}{ Equity REITs } \\
\hline Sort Procedure & $\delta_{0}$ & $\mathrm{~T}\left(\delta_{0}\right)$ & PROB & $\delta_{2}$ & $\mathrm{~T}\left(\delta_{2}\right)$ & PROB & $x_{i}^{2}$ \\
\hline SP500/VWFRC & .0110 & 5.39 & .00 & .0386 & 4.56 & .00 & 5.765 \\
\hline MGCI/VWFRC & .0127 & 6.57 & .00 & .0371 & 4.56 & .00 & 5.765 \\
\hline SMI/VWFRC & .0117 & 4.11 & .00 & .0233 & 4.10 & .00 & 5.765 \\
\hline USMII/VWFRC & .0123 & 6.89 & .00 & .0157 & 3.54 & .00 & 5.765 \\
\hline USMI $2 /$ VWFRC & .0103 & 3.52 & .00 & .0160 & 3.62 & .00 & 5.764 \\
\hline ICM/VWFRC & .0138 & 6.03 & .00 & .0246 & 2.96 & .01 & 5.765 \\
\hline VWFRC/SPSO0 & .0148 & 8.49 & .00 & .0342 & 4.83 & .00 & 5.765 \\
\hline VWFRC/MGCI & .0158 & 7.33 & .00 & .0265 & 2.81 & .01 & 5.765 \\
\hline VWFRC/SMI & .0156 & 7.55 & .00 & .0196 & 3.39 & .00 & 5.765 \\
\hline VWFRCIUSMII & .0145 & 7.07 & .00 & .0157 & 3.38 & .00 & 5.765 \\
\hline VWFRC/USMI2 & .0158 & 7.69 & .00 & .0092 & 2.43 & .02 & 5.765 \\
\hline VWFRC/ICM & .0136 & 7.65 & .00 & .0265 & 2.92 & .01 & 5.765 \\
\hline
\end{tabular}

Note: The PROB is the two-tailed probability that the associated coefficient is not significantly different from zero. 
Table 5. Tests of integration using ACLI data

\begin{tabular}{|c|c|c|c|c|c|c|c|}
\hline \multicolumn{8}{|c|}{ All ACLI and EREITs } \\
\hline Sort Procedure & $\gamma_{0}$ & $T\left(\gamma_{0}\right)$ & PROB & $\gamma_{2}$ & $\mathrm{~T}\left(\gamma_{2}\right)$ & PROB & $x_{i}^{2}$ \\
\hline SP500/VWACLI & .0223 & 4.09 & .00 & -.0100 & -1.23 & .23 & 5.766 \\
\hline MGCI/VWACLI & .0300 & 5.44 & .00 & -.0119 & -1.05 & .30 & 5.764 \\
\hline SMI/VWACLI & .0035 & 0.58 & .57 & .0365 & 2.90 & .01 & 5.765 \\
\hline USMII/VWACLI & -.0035 & -.62 & .54 & .0423 & 2.53 & .02 & 5.769 \\
\hline USMI2/VWACLI & -.0065 & -1.19 & .24 & .0272 & 2.93 & .01 & 5.765 \\
\hline ICM/VWACLI & .0167 & 3.39 & .00 & -.0057 & -58 & .57 & 5.768 \\
\hline VWACLI/SP500 & .0244 & 3.59 & .00 & -.0204 & -1.55 & .13 & 5.764 \\
\hline VWACLI/MGCI & .0376 & 6.39 & .00 & -.0235 & -2.05 & .05 & 5.766 \\
\hline VWACLI/SMI & -.0064 & -.56 & .58 & .0847 & 2.93 & .01 & 5.764 \\
\hline VWACLI/USMII & .0043 & 0.79 & .43 & .0084 & 0.91 & .37 & 5.766 \\
\hline VWACLI/USMD2 & -.0121 & -1.92 & .06 & .0302 & 2.69 & .01 & 5.765 \\
\hline VWACLI/ICM & .0010 & 1.54 & .13 & .0281 & 2.32 & .03 & 5.765 \\
\hline \multicolumn{8}{|l|}{ ACLI Properties } \\
\hline Son Procedure & $\gamma_{0}$ & $T\left(\gamma_{0}\right)$ & PROB & $\gamma_{2}$ & $\mathrm{~T}\left(\gamma_{2}\right)$ & PROB & $x^{2}$ \\
\hline SP500/VWACLI & .0248 & 3.30 & .00 & -.0026 & -.22 & .83 & 5.764 \\
\hline MGCI/VWACLI & .0264 & 3.58 & .00 & -.0022 & -.20 & .84 & 5.764 \\
\hline SMI/VWACLI & .0245 & 3.31 & .00 & .0050 & 0.46 & .65 & 5.764 \\
\hline USMI/VWACLI & .0243 & 3.60 & .00 & .0115 & 1.11 & .27 & 5.764 \\
\hline USMI2/VWACLI & .0225 & 3.45 & .00 & .0169 & 1.68 & .10 & 5.765 \\
\hline ICM/VWACLI & .0238 & 3.54 & .00 & .0030 & 0.30 & .77 & 5.764 \\
\hline VWACLI/SP500 & .0248 & 3.30 & .00 & -.0026 & -.22 & .83 & 5.764 \\
\hline VWACLI/MGCI & .0264 & 3.58 & .00 & -.0022 & -.20 & .84 & 5.764 \\
\hline VWACLI/SMI & .0245 & 3.31 & .00 & .0050 & 0.46 & .65 & 5.764 \\
\hline VWACLI/USMII & .0243 & 3.60 & .00 & .0115 & 1.11 & .27 & 5.764 \\
\hline VWACLI/USMI2 & .0225 & 3.45 & .00 & .0169 & 1.68 & .10 & 5.765 \\
\hline VWACLI/ICM & .0238 & 3.54 & .00 & .0030 & 0.30 & .77 & 5.764 \\
\hline \multicolumn{8}{|l|}{ Equity REITs } \\
\hline Sort Procedure & $\gamma_{0}$ & $T\left(\gamma_{0}\right)$ & PROB & $\gamma_{2}$ & $T\left(\gamma_{2}\right)$ & PROB & $x_{i}^{2}$ \\
\hline SP500/VWACLI & .0362 & 4.51 & .00 & -.0006 & -.03 & .98 & 5.764 \\
\hline MGCI/VWACLI & .0398 & 6.18 & .00 & -.0052 & -.20 & .84 & 5.765 \\
\hline SMI/VWACLI & .0474 & 0.99 & .33 & -.3589 & -.98 & .33 & 5.765 \\
\hline USMII/VWACLI & .0120 & 1.49 & .15 & -.0637 & -2.40 & .02 & 5.765 \\
\hline USMI2/VWACLI & .0314 & 1.23 & .23 & .1884 & 1.16 & .26 & 5.765 \\
\hline ICM/VWACLI & .0664 & 1.14 & .26 & .3397 & 0.95 & .35 & 5.764 \\
\hline VWACLI/SP500 & .0195 & 1.28 & .21 & -.1149 & -1.53 & .14 & 5.766 \\
\hline VWACLI/MGCI & .0329 & 1.13 & .27 & .2758 & 1.06 & .30 & 5.765 \\
\hline VWACLI/SMI & .0482 & 0.67 & .51 & .5370 & 0.64 & .53 & 5.765 \\
\hline VWACLI/USMII & .1076 & 1.41 & .17 & -.1222 & -1.83 & .08 & 5.764 \\
\hline VWACLI/USMI2 & .0164 & 0.26 & .80 & .6615 & 0.55 & .59 & 5.764 \\
\hline VWACLI/ICM & .0326 & 1.28 & .21 & .2211 & 1.54 & .13 & 5.765 \\
\hline
\end{tabular}

Note: The PROB is the two-tailed probability that the associated coefficient is not significantly different from zero. 
Table 6 . Tests of segmentation using ACLI data

\begin{tabular}{|c|c|c|c|c|c|c|c|}
\hline \multicolumn{8}{|l|}{ All ACLI and EREITs } \\
\hline Sort Procedure & $\delta_{0}$ & $\mathrm{~T}\left(\delta_{0}\right)$ & PROB & $\delta_{2}$ & $\mathrm{~T}\left(\delta_{2}\right)$ & PROB & $x_{1}^{2}$ \\
\hline SP500/VWACLI & .0137 & 1.96 & .06 & .0335 & 2.78 & .01 & 5.763 \\
\hline MGCI/VWACLI & .0150 & 2.32 & .03 & .0284 & 2.33 & .03 & 5.765 \\
\hline SMI/VWACLI & .0164 & 2.82 & .01 & .0145 & 2.17 & .04 & 5.764 \\
\hline USMII/VWACLI & .0265 & 4.31 & .00 & .0049 & 1.19 & .24 & 5.764 \\
\hline USMI2/VWACLI & .0262 & 4.11 & .00 & -.0007 & -.18 & .86 & 5.765 \\
\hline ICM/VWACLI & .0134 & 2.16 & .04 & .0226 & 2.83 & .01 & 5.764 \\
\hline VWACLI/SP500 & .0131 & 1.71 & .10 & .0334 & 2.91 & .01 & 5.765 \\
\hline VWACLI/MGCI & .0217 & 3.74 & .00 & .0159 & 1.32 & .20 & 5.765 \\
\hline VWACLI/SMI & .0184 & 2.87 & .01 & .0164 & 2.09 & .04 & 5.765 \\
\hline VWACLI/USMII & .0238 & 3.89 & .00 & .0031 & 0.61 & .55 & 5.765 \\
\hline VWACLI/USMI2 & .0220 & 3.44 & .00 & .0031 & 0.73 & .47 & 5.765 \\
\hline VWACLI/ICM & .0165 & 2.45 & .02 & .0151 & 1.85 & .07 & 5.765 \\
\hline \multicolumn{8}{|l|}{ ACLI Properties } \\
\hline Sort Procedure & $\delta_{0}$ & $\mathbf{T}\left(\delta_{\mathrm{a}}\right)$ & PROB & $\delta_{2}$ & $\mathrm{~T}\left(\delta_{2}\right)$ & PROB & $x_{i}^{2}$ \\
\hline SP500/VWACLI & .0246 & 2.99 & .01 & -.0262 & -1.41 & .17 & 5.764 \\
\hline MGCIVWWACLI & .0251 & 2.86 & .01 & -.0483 & -2.17 & .04 & 5.765 \\
\hline SMI/VWACLI & .0244 & 2.96 & .01 & -.0115 & -1.75 & .09 & 5.764 \\
\hline USMII/VWACLI & .0241 & 2.96 & 01 & -.0198 & -1.79 & .08 & 5.764 \\
\hline USMI2/VWACLI & .0233 & 2.77 & .01 & -.0146 & -2.35 & .03 & 5.765 \\
\hline ICM/VWACLI & .0229 & 2.85 & .01 & -.0156 & -1.84 & .08 & 5.764 \\
\hline VWACLI/SP500 & .0246 & 2.99 & .01 & -.0262 & -1.41 & .17 & 5.764 \\
\hline VWACLI/MGCI & .0251 & 2.86 & .01 & -.0483 & -2.17 & .04 & 5.765 \\
\hline vWACLI/SMI & .0244 & 2.96 & .01 & -.0115 & -1.75 & .09 & 5.764 \\
\hline VWACLI/USMII & .0241 & 2.96 & .01 & -.0198 & -1.79 & .08 & 5.764 \\
\hline VWACLI/USMI2 & .0233 & 2.77 & .01 & -.0146 & -2.35 & .03 & 5.765 \\
\hline VWACLI/CM & .0229 & 2.85 & 01 & -.0156 & -1.84 & .08 & 5.764 \\
\hline \multicolumn{8}{|l|}{ Equity REITs } \\
\hline Sort Procedure & $\delta_{0}$ & $\mathbf{T}\left(\delta_{0}\right)$ & PROB & $\delta_{2}$ & $\mathbf{T}\left(\delta_{2}\right)$ & PROB & $x_{i}^{2}$ \\
\hline SP500/VWACLI & .0345 & 6.65 & .00 & .0101 & 1.12 & .27 & 5.764 \\
\hline MGCI/VWACLI & .0233 & 3.05 & .00 & .0219 & 1.42 & .17 & 5.765 \\
\hline SML/VWACLI & .0210 & 2.96 & 01 & .0148 & 1.68 & .10 & 5.765 \\
\hline USMIIVWACLI & .0260 & 3.68 & .00 & .0073 & 1.35 & .19 & 5.765 \\
\hline USMI2/VWACLI & .0218 & 2.70 & 01 & .0064 & 1.29 & .21 & 5.765 \\
\hline ICM/VWACLI & .0283 & 4.28 & .00 & .0185 & 2.19 & .04 & 5.765 \\
\hline VWACLI/SP500 & .0259 & 3.95 & .00 & .0105 & 0.96 & .34 & 5.764 \\
\hline VWACLI/MGCI & .0218 & 3.04 &.$\infty$ & .0236 & 1.71 & .10 & 5.765 \\
\hline VWACLISMI & .0234 & 3.61 & .00 & .0122 & 1.53 & .14 & 5.765 \\
\hline VWACLI/USMII & .0244 & 3.82 & .00 & .0076 & 1.38 & .18 & 5.764 \\
\hline VWACLI/USMI2 & .0223 & 3.18 & .00 & .0079 & 1.57 & .13 & 5.764 \\
\hline VWACLI/ICM & .0247 & 3.68 & .00 & .0148 & 1.87 & .07 & 5.764 \\
\hline
\end{tabular}

Note: The PROB is the two-tailed probability that the associated coefficient is not significantly different from zero.

Table 5 and table 6 show that, as is the case with table 3 and table 4, the two-factor models in equations (13) and (14) are also consistent with the data for the tests of integration and segmentation, respectively, when the ACLI properties are used in lieu of FRC properties. Although the two-factor model for integration in equation (13) holds regardless of whether FRC or ACLI properties are utilized, different conclusions arise with respect to which version of the CAPM fits the data. For FRC properties, the Sharpe-Lintner version of the CAPM holds for all market proxies and sorting procedures at the 5 percent level of significance except for the SMI/VWFRC and ICM/VWFRC sorting schemes even though $\gamma_{0}$ is 
consistently negative. In contrast, the Black version of the CAPM holds for ACLI properties at the 5 percent level of significance across all market proxies and grouping procedures with the $\gamma_{0}$ term consistently positive.

\section{Summary and Conclusions}

We find evidence that the commercial real estate market is segmented from the stock market. However, whether indirect barriers or legal constraints represent the prime catalyst for the existence of segmentation depends not only on whether appraised values or imputed sales prices are used 10 compute real estate returns but also on the market proxy chosen. The analysis of the FRC data indicates that indirect barriers such as the cost, amount, and quality of information are the major source of segmentation since we find that equity REITs are integrated with the stock market, but the commercial real estate that underlies these equity REITs is segmented from the stock market. In contrast, it is unclear whether the commercial real estate market is integrated with or segmented from the stock market and whether segmentation arises as the result of indirect barriers or legal constraints when the ACLI data are evaluated. In other words, we are unable to reject at least one of the competing hypotheses relative to the ACLI data. The commercial real estate market appears to be integrated with the stock market when the tests of integration are performed. However, the tests of segmentation indicate that segmentation exists between the two asset markets with the market proxy chosen and the sorting procedure used, influencing whether segmentation arises due to indirect constraints or legal barriers. Weak evidence exists, however, that segmentation is due to indirect constraints when a 20 percent level of significance is used in conjunction with the test for segmentation.

Conflicting evidence also exists as to which version of the CAPM holds. For FRC properties, the Sharpe-Lintner version of the CAPM obtains for all market proxies and sorting procedures in general. In contrast, the Black version of the CAPM holds for ACLI properties across all market proxies and grouping procedures.

Although the CAPM is used in investigating whether the commercial real estate market is integrated with or segmented from the stock market, we could interpret our results as a test of a twofactor arbitrage pricing model, as Jorion and Schwartz (1986) note with the factors known in advance. These two factors are the return on the commercial real estate market and the return on the overall market portfolio. From an APT perspective, the results of our study indicate that FRC properties do not fit the context of a one-factor pricing model since the commercial real estate market factor is priced in addition to the overall market factor. On the other hand, it is unclear whether a one-factor pricing 
model is appropriate for ACLI properties. Ultimately, what is required are better real estate return data since the use of imputed returns from ACLI data represents only a second best alternative.

\section{Appendix A}

The property associated with each general real estate category are as follows:

Equity REITs: California REIT, EastGroup Properties, Federal Realty, First Union, Hollywood Park, Hotel Investors, HRE Properties, Indiana-Florida REIT, IRT, New Plan Realty, Pennsylvania REIT, Property Capital, Property Trust of America, REIT of California, Santa Anita Realty, USP REIT, Washington REIT, and Western Investment.

ACLI Commercial Real Estate: Retail: South, West. Office: North, South, East, West. Industrial: South, East, West.

FRC Commercial Real Estate: Region: North, South, East, West. Type: Hotel \& Motel and Apartments. Offices: North, South, East, West. Retail: North, South, East, West. R\&D Industrial: North, South, East, West. Industrial Warehouse: North, South, East West.

\section{Appendix B}

The return and market value associated with each asset class used to construct the portfolio return and portfolio weights in table 1 are obtained as follows:

1. Cash Equivalents. Returns on Treasury Bills with a three-month maturity are from issues of Economic Indicators. Yields on 90- to 119-day commercial paper and 90-day bankers' acceptances are obtained from the Federal Reserve Bulletin. Values for three-month Treasury Bills, 90- to 119-day commercial paper, and 90-day bankers' acceptances are taken from the Federal Reserve Bulletin.

2. Corporate Bonds, U.S. Government Bonds, and Mortgage-Backed Bonds. Returns on and aggregate market values for corporate bonds, U.S. government bonds, and mortgage-backed bonds are obtained from the Shearson-Lehman publication. The Bond Market Annual Report. Each series is mutually exclusive of one another and contains both intermediate term (one to ten years) and long term (ten years or more) bonds.

3. Common Stock. The return and market value associated with the $\mathrm{MGCl}$ index are taken from various issues of Media General Financial Weekly.

4. Commercial Real Estate. Aggregate value estimates for nonresidential commercial real estate are taken from Musgrave (1981) and subsequent issues of the Survey of Current Business. The series for 
current dollar net stock of noncorporate nonresidential structures is chosen to avoid double-counting corporate real estate. Farm structures are factored out from this total. The aggregate land value is obtained from the Board of Governors of the Federal Reserve System publication. Balance Sheets for the U.S. Economy 1945-1986. The mortgage amount outstanding for nonresidential income-producing properties taken from the Federal Reserve's Annual Statistical Series is subtracted from the total market value to yield the equity value.

The aggregate value for multifamily residential structures appears in the U.S. Department of Commerce book. Fixed Reproducible Tangible Wealth in the United States 1925-1985. The series utilized is the current dollar net stock of nonfarm five or more unit structures. Aggregate land value for apartments is taken from Balance Sheets for the U.S. Economy 1945-1986. Mortgage debt for apartments contained in the Annual Statistical Series of the Federal Reserve is subtracted from the total multifamily value to obtain the equity apartment estimate. The resulting apartment equity is added to the equity for nonresidential income properties to arrive at the total] equity of commercial nonfarm real estate.

5. Farm Real Estate. Farm returns are based on the average quarterly price per acre for 11 types of farmland classified with respect to geographic location and productivity from the Federal Reserve Bank of Kansas City. ${ }^{14}$ Income is obtained from the U.S. Department of Agriculture publications, Farm Real Estate Market Developments: Outlook and Situation and Agricultural Land Values and Markets: Outlook and Situation. The market value of farms are taken from Farm Real Estate Market Developments and Agricultural Land Values and Markets. Real estate debt reported in Economic Indicators of the Farm Sector: National Financial Summary 1985 is subtracted from this total value to generate total farm equity. Quarterly market values are obtained from year-end values through a straight-line interpolation process.

6. Single-Family Homes. Monthly weighted average sale prices on new and existing homes for 27 metropolitan statistical areas are obtained from the Federal Home Loan Bank Board (FHLBB). ${ }^{15}$ The data include only houses financed with conventional first mortgage loans. A three-month moving average series is employed since the average price reported for a month covers all loans entered on a lender's books during the first five working days of each month. The closed loans thus represent sales contracts written anywhere from one week to two months previously. Monthly median rents, vacancies, and operating expenses are obtained from the U.S. Bureau of the Census publication. Annual Housing Survey: Summary of Housing Characteristics for Selected Metropolitan Areas, H-171 Series. The aggregate value of single family residential structures is taken from the U.S. Department of Commerce 
publication, Fixed Reproducible Tangible Wealth in the United States 1925-1985. The series used is the current dollar net stock of nonfarm one- to four-unit structures. Aggregate residential land values are taken from Balance Sheets for the U.S. Economy 1945-1986. The aggregate home mortgage debt quoted in the Federal Reserve publication Annual Statistical Series is next subtracted from this total value to arrive at single-family home equity. Quarterly market values are obtained from year-end values through a straight-line interpolation process.

\section{Acknowledgments}

The authors wish to thank Larry Lang, Ah Yee Lee, and two anonymous referees for their constructive comments on this article.

\section{References}

Abel, Andrew and Mishkin, Frederic. "An Integrated View of Tests of Rationality, Market Efficiency and the Shon-Run Neutrality of Monetary Policy." Journal of Monetary Economics 11 (1983), 3-24.

Bajic, Vladimir, "Housing Market Segmentation and Demand for Housing Attributes: Some Empirical Findings." AREUEA Journal 13 (1985), 58-75.

Barro, R.J. "Unanticipated Money Growth and Unemployment in the United States." American Economic Review 67 (1977), 101-115.

Blume, Marshall and Friend, Irwin. "A New Look at the Capital Asset Pricing Model." Journal of Finance 28 (1973), 19-33.

Bureau of Labor Statistics, BLS Handbook of Methods Volume II: The Consumer Price Index. Washington, DC: US. Government Printing Office, 1984.

Dimson, Elroy. "Risk Measurement When Shares are Subject to Infrequent Trading." Journal of Financial Economics 7 (1979), 197-226.

Errunza, Vihang and Losq, Etienne. "International Asset Pricing under Mild Segmentation: Theory and Test." Journal of Finance 40 (1985), 105-124.

Fama, Eugene F. and Schwert, G. William. "Asset Returns and Inflation." Journal of Financial Economics 5 (1977), 115-146.

Gallant, A, Ronald, "Seemingly Unrelated Nonlinear Regressions." Journal of Econometrics 3 (1975). 35 50. 
Gibbons, Michael, "Multivariate Tests of Financial Model." Journal of Financial Economics 10 (1982), 327.

Goodman, Allen C, "Hedonic Prices, Price Indices, and Housing Markets." Journal of Urban Economics 5 (1978), 471-484.

.."Submarkets within Urban Areas: Definitions and Evidence." Journal of Regional Science 21 (1981), 1975-185.

Grissom, Terry, Hartzell, David, and Liu, Crocker H, "An Approach to Industrial Real Estate Market Segmentation and Valuation Using the Arbitrage Pricing Paradigm," AREUEA Journal 15 (1987), 199-219.

Hoffman, Dennis, Low, Stuart, and Schlagenhauf, Don. "Tests of Rationality, Neutrality, and Market Efficiency," Journal of Monetary Economics M (1984), 339-363.

Ibbotson, Roger G, and Fail, Carol L. "The United States Market Wealth Portfolio," Journal of Portfolio Management 6 (1979), 82-92.

Jobson, J.D, and Korkie, Bob. "Potential Performance arid Tests of Portfolio Efficiency," Journal of Financial Economics 10 (1982), 433-446.

Jorion, Philippe and Schwartz, Eduardo. "Integration vs. Segmentation in the Canadian Stock Market." Journal of Finance 41 (1986), 603-616.

Liu, Crocker H, "Market Imperfections, Omitted Asset Markets, and Abnormal Real Estate Returns: A Theoretical and Empirical Investigation." Ph.D. dissertation, University of Texas. Austin. 1988.

Mishkin, Frederic. A Rational Expectations Approach to Macroeconometrics: Testing Policy Ineffectiveness and Efficient Markets Models. Chicago: University of Chicago Press, 1983.

Musgrave, John C. "Fixed Capital Stock in the United States: Revised Estimates." Survey of Current Business 61 (1981), 57-68.

."Fixed Reproducible Tangible Wealth in the United States," Survey of Current Business 62 (1982), 33-46.

."Fixed Reproducible Tangible Wealth in the United States. 1979-1982." Survey of Current Business 63 (1983), 62-65.

"Fixed Reproducible Tangible Wealth in the United States, 1980-1983." Survey of Current Business 64 (1984), 54-57.

. "Fixed Reproducible Tangible Wealth in the United States, Revised Estimates," Survey of Current Business 66 (1986a), 51-75. 
."Fixed Reproducible Tangible Wealth in the United States, 1982-1985," Survey of Current Business 66 (1986b), 36-39.

."Fixed Reproducible Tangible Wealth in the United States, 1983-1986," Survey of Current Business 67 (1987), 100-103,

Pagan, Adrian, "Econometric Issues in the Analysis of Regressions with Generated Regressors." International Economic Review 25 (1984), 221-247.

Richardson, David and Thalheimer. Richard, "On the Use of Grouping Methods in the Analysis of Residential Housing Markets." Regional Science and Urban Economics 12 (1982), 285-304.

Roll, Richard, "A Critique of the Asset Pricing Theory's Tests," Journal of Financial Economics 4 (1977), 129-176.

Schnare, Ann and Struyk, Raymond, "Segmentation in Urban Housing Markets." Journal of Urban Economics 3 (1976), 146-166.

Sonstelie, Jon and Portney, Paul, "Gross Rents and Market Values: Testing the Implications of Tiebout's Hypothesis," Journal of Urban Economics 1 (1980), 102-118.

Stambaugh, Robert F. "On the Exclusion Assets from Tests of the Two Parameter Model: A Sensitivity Analysis," Journal of Financial Economics 10 (1982), 237-268.

Stapleton, R.C. and Subrahmanyam, M.G. "Market Imperfections, Capital Market Equilibrium, and Corporation Finance." Journal of Finance 32 (1977), 307-319.

Stehle, Richard, "An Empirical Test of the Alternative Hypotheses of National and International Pricing of Risky Assets," Journal of Finance 32 (1977), 493-502.

Straszheim, M. "Hedonic Estimation of Housing Prices: A Further Comment." Review Economics and Statistics 56 (1974), 404-406.

U.S. Department of Commerce. Fixed Reproducible Tangible Wealth in the United States, 1925-85. Washington, DC: US. Government Printing Office, 1986.

\footnotetext{
${ }^{1}$ However, real estate literature exists on whether the commercial real estate submarket or the housing submarket is segmented from an intra-asset perspective. In one of the few studies on segmentation in the commercial real estate market, we find evidence that the commercial real estate market is segmented according to regions (cf. Grissom, Hartzell, and Liu, 1987). Bajic (1985), Goodman (1978. 1981), Richardson and Thalheimer (1982), Straszheim (1974), Schnare and Struyk (1976), and Sonstalie and Portney (1980) also find evidence that is consistent with segmented housing markets.

${ }^{2}$ The findings of Stehle are also indeterminate since the study uses a U.S. index which is highly collinear with the world index. Errunza and Losq, on the other hand, cite the kinds of restrictions imposed and the market proxies used for their weak results.

${ }^{3}$ This test allows one to distinguish not only whether indirect barriers or legal restrictions are the prime determinant of segmentation but also which type of restriction influences asset pricing. Canadian stocks are analyzed relative to the North American market with firms interlisted on both stock markets used to detect the
} 
source of segmentation. The study finds that statutory restrictions rather than indirect barriers are the major source of segmentation.

${ }^{4}$ The period evaluated does encompass both an inflation and disinflation economic environment. Inflation characterizes the period from the second quarter of 1978 to the end of 1981, while disinflation is associated with the post-1981 period. A positive return bias prevalent in most real estate Investment studies is thus absent in the present study.

${ }^{5}$ The capitalization rate is defined as the net operating income for a property divided by its selling price. The prices that result from dividing net operating income by the capitalization rate do not represent specific market transactions. However, the cap rates are computed from specific market transactions and thus provide an indicator of marketwide variations in sale prices. The authors feel that this represents the second best alternative in lieu of actual sales prices since smoothing problems associated with appraised values are obivated. This process is analogous to backing out stock prices given information on the dividend yield and the amount of the dividend in each period.

${ }^{6}$ The index is calculated as the share price of common shares multiplied by the number of shares outstanding for all corporations traded on the NYSE, ASE, and NASDAQ. Rights, preferred stock, and, when issued, stocks are excluded. The index is adjusted for all stock splits, stock dividends, delistings, suspensions, or halts of trading or dividend distributions through a recalculation of the base market value. Ibbotson and Fall (1979) use the market value of the $\mathrm{MGCl}$ as a proxy for the aggregate value of all stocks to construct a U.S. market index.

${ }^{7}$ Double-counting might arise since multiple financial claims on the same underlying asset are present. Corporations holding common stock of another corporation is one example of this dilemma. Another example is real estate and real estate mortgages. The current study attempts to avoid the latter type of double-counting through using only the total equity value for various property types. Some types of double-counting still remain, however, with the impact of omitted assets unknown.

${ }^{8}$ The actual model that Jorion and Schwartz (1986) use to test whether integration exists includes one lead and one lag added to each independent variable using the Dimson (1979) correction for thin trading since the Canadian stocks used in their test suffer from thin trading. The actual model that Jorion and Schwartz test is, therefore,

$$
\tilde{R}_{i t}=\gamma_{0}\left(1-\beta_{i M}\right)+\gamma_{2} \beta_{i C \mid M}+\sum_{j=-1}^{+1} \beta_{i j M} \tilde{R}_{M t+j}+\sum_{j=-1}^{+1} \beta_{i j \mid} \mid \tilde{v}_{C \mid M t+j}+\tilde{e}_{i t}
$$

with

$$
\beta_{i M}=\sum_{j=-1}^{+1} \beta_{i j M} \text { and } \beta_{i C \mid M}=\sum_{j=-1}^{+1} \beta_{i j C \mid M} \text {. }
$$

The current study does not use the Dimson correction for thin trading since the imputed sale prices derived from ACU cap rates implicitly assume that continuous trading exists. The appraised values that underlie the FRC returns, on the other hand, represent a subjective correction for thin trading by definition.

${ }^{9}$ The only exception to this is when the USMI1 is chosen as the overall market portfolio and the value-weighted ACLI portfolio represents the commercial real estate market proxy In this case, the correlation is only marginally significant from zero at the 5 percent level of significance and is not statistically significant from zero at the 10 percent level of significance.

${ }^{10}$ The Jobson-Korkie modification to the LRT statistic is

$$
\left(T-N_{1}-\frac{N_{2}}{2}-1\right)\left[\ln \left|\hat{\Sigma}_{r}\right|-\ln \left|\hat{\Sigma}_{\mu}\right|\right] \sim \chi_{N_{2}}^{2}
$$

where $\mathrm{N}=\mathrm{N}_{1}+\mathrm{N}_{2}$ is the $N$ regression equations, $\mathrm{T}$ is the number of time-series observations, $\mathrm{N}_{1}$ is the number of linear or nonlinear restrictions on a system of $N$ equations, $|\widetilde{\Sigma r}|$ is the determinant of the contemporaneous variance-covariance matrix estimated from the residuals of the constrained system, and $|\widetilde{\Sigma u}|$ is the determinant of the contemporaneous variance-covariance matrix estimated from the residuals of the unconstrained system, ${ }^{11}$ The portfolio formation process is not adhered to with respect to grouping ACLI properties into nine commercial real estate portfolios since only nine ACLI property funds are available.

${ }^{12}$ Interested securities from a stock perspective are securities that are listed on a U.S. stock exchange in addition to one or more foreign stock markets such as the Canadian stock market. Although EREITs do not technically trade 
in both the stock and real estate markets, the real estate that underlies the equity REITs does trade in the commercial real estate market.

${ }^{13}$ A REIT must have a minimum of 100 shareholders with not more than 50 percent of the shares owned by five or fewer individuals.

${ }^{14}$ The Federal Reserve Bank of Kansas City is the only federal reserve bank that has continuous price data on farm real estate over the study period. The price of farmland for the appropriate states under the jurisdiction of other federal reserve banks, such as the Federal Reserve Bank of Dallas, are of more recent origin (1985).

${ }^{15}$ The FHLBB price series differs from the home purchase price component of the CPI index which both Fama and Schwert (1977) and Stambaugh (1982) employ. Properties that underlie the former series are financed with conventional loans while FHA loans correspond to the latter series. Conventional loans account for the majority of home sales. FHA loans in contrast currently account for about 7 percent of all home sales, according to the Bureau of Labor Statistics (1984). Another deficiency with the FHA data is that only lower priced homes are represented given legal price ceiling constraints. The CPI housing index, however, does possess an advantage over the FHLBB series in that it measures the price appreciation of a standard home. The CPI Home Purchase Price Index is not used in the present study since the series ended in 1984. 